\title{
TERCEIRA ETAPA MÉTODO CANG URU: convergência de práticas investigativas e cuidado com famílias em atendimento ambulatoriala
}

\author{
M árcia BORCK ${ }^{b}$, E vanguelia Kotzias A therino dos SA NT OS
}

\section{RESUM 0}

T rata-se de uma Pesquisa Converg ente-A ssistencial, de natureza qual itativa, que teve como objetivos investigar a experiência no processo de adaptação de famílias na terceira etapa do M étodo Canguru com recém-nascidos prétermo e/ ou de baixo peso e implementar a consulta de enfermagem dentro dos quatro modos adaptativos da T eoria de Roy. D esenvolvido no período de outubro de 2006 a fevereiro de 2007 em um H ospital U niversitário. Os sujeitos foram seis mães, familiares e seus bebês. A coleta de dados foi real izada atr avés do processo de cuidar do modelo adaptativo de Roy, utilizando as técnicas de observação e da entrevista semi-estruturada. 0 processo de análise ocorreu através da apreensão, síntese, teorização e transferência. Os resultados mostram a necessidade de fortalecer o papel da família na desospital ização, a comunicação entre a equipe interdisciplinar e rever critérios de alta da terceira etapa.

D escritores: Enfer magem neonatal. R ecém-nascido prematuro. Recém-nascido de baixo peso. Relações mãe-filho.

\section{RESUMEN}

E s una Investigación Convergente-Asistencial, cualitativo, sus objetivos fueron investigar la experiencia en el proceso de adaptación de familias en la tercera etapa del M étodo Canguro con recién nacidos pretérmino y/ o de bajo peso, implementar la consulta de enfermería dientro de las cuatro modos adaptativos de la Teoría de R oy. F ue desarrollada en el período de octubre de 2006 a febrero de 2007 en un H ospital U niversitario. L os sujetos fueron seis madres, los familiares y sus bebés. L a recolección de los datos fue realizada a través del proceso de cuidar del modelo adaptativo de R oy, utilizando las técnicas de observación y la entrevista parcialmente estructurada. EI proceso de análisis se hizo por medio de la aprehensión, síntesis, teorización y transferencia. L os resultados muestran la necesidad de fortalecer el papel de la familia en la deshospitalización, la comunicación entre el equipo disciplinario y rever criterios de alta de la tercera etapa.

D escriptores: E nfermería neonatal. P rematuro. R ecién nacido de bajo peso. Relaciones madre hijo.

Título: Tercera etapa M étodo Canguro: convergencia de prácticas de investigación y cuidado con familias en la atención ambulatoria.

\section{ABST RACT}

This study deals with qualitative, Convergent-Care R esearch whose objectives are to investigate the adaptation process experience of families in thisthird stage of theK angaroo $\mathrm{M}$ ethod with prematureand/ or low weight new bor ns, to implement a nursing visit in reference to the four adaptive modes of the R oy Theory. The study was developed from 0 ctober, 2006 to F ebruary, 2007 in a U niversity $\mathrm{H}$ ospital. The subjects w ere six mothers, family members, and their babies. D ata was collected through R oy's adaptive care process model, using observation techniques and semi- structured interviews. The data analysis process was carried out through apprehension, synthesis, theorization, and transference. The results show the need to strengthen the role of the family in the patient's leave from the hospital and the communication among the interdisciplinary team, as well as to rethink the criteria for releasing in the third stage.

D escriptors: N eonatal nursing. Infant, premature Infant, low birth weight. M other-child relations.

T itle: T hird stage of the Kangaroo M ethod: converging investigative and care practices with families in outpatient care

\footnotetext{
a A rtigo originado da dissertação apresentada em 2007 ao Programa de Pós-G raduação em E nfer magem da U niversidade F ederal de Santa Catarina (USFC).

${ }^{b} \mathrm{M}$ estre em E nfer magem, E nfermeira do Serviço de N eonatologia do H ospital U niversitário da U F SC, Consultora para o M étodo Canguru no Brasil do M inistério da Saúde, Florianópolis, Santa Catarina, Brasil.

c D outora em Enfermagem, Professora Associada do D epartamento de Enfermagem e do Programa de Pós-Graduação em Enfermagem da U F SC, Líder do Grupo de Pesquisa em Enfermagem na Saúde da M ulher e do Recém-N ascido, F lorianópolis, Santa Catarina, Brasil.
} 


\section{INT RODUÇÃO}

Os processos dos cuidados assistenciais em $\mathrm{N}$ eonatologia têm suas bases descritas desde 0 século XIX, quando Pierre Budin, médico obstetra francês, em 1900, estabeleceu pela primeira vez as modalidades de vigilância e cuidados dos bebês de baixo peso ao nascer: manutenção do equilíbrio térmico, prevenção de infecções por meio de assepsia e alimentação com leite do peito ${ }^{(1)}$.

0 modelo de assistência neonatal que se consolidou neste século, em quase toda cultura ocidental, exclui os pais dos cuidados aos recémnascidos pré-termo e evolui com grandes conquistas técnico-científicas. 0 uso de tecnologias avançadas de terapia intensiva como incubadoras, berços de calor radiante, equipamentos para assistência ventilatória, alimentação parenteral, antibióticos de última geração, contribuíram com significativos avanços na área neonatal permitindo maior sobrevida de recém-nascidos pré-termo ${ }^{(2)}$.

$\mathrm{N}$ os dias atuais os cuidados neonatais tiveram influência da introdução de outras tecnologias como o uso do corticóide antenatal, o uso do surfactante neonatal, a ventilação de alta frequência e o uso de óxido nítrico. Isso colaborou para uma ampla mudança no perfil da mortalidade infantil. Entretanto, ainda existem alguns problemas associados à atenção neonatal, à exemplo do maior tempo de internação, com separação precoce e prolongada da mãe-filho-família, menor incidência e prevalência do aleitamento materno, maior exposição do neonato a complicações que cursam com graves seqüelas e maior demanda da atenção especial e de al to custo ${ }^{(2)}$.

No Brasil, o movimento para divulgar o M étodo Canguru (MC) de assistência ao pré-termo ou recém-nascido de baixo peso iniciou-se em 1999, com a Conferência Nacional $M$ étodo Canguru no Rio de Janeiro. Esta tinha como objetivos divulgar o M étodo como alter nativa viável e segura de atenção perinatal, difundir os benefícios sócio-econômicos e possibilitar que dirigentes de serviços de saúde, autoridades sanitárias, formuladores de políticas sociais e formadores de opinião conhecessem os fundamentos científicos e o impacto social desta iniciativa ${ }^{(3)}$.

A partir de então surge a participação do M inistério da Saúde do Brasil, lançando a Norma de Atenção Humanizada ao Recém-nascido de Baixo Peso - Projeto Canguru, por meio da Por- taria no 693 do M inistério da Saúde (M S)(4), que visa o estabelecimento de uma contínua adequação tanto na abordagem técnica quanto das posturas que impliquem em mudanças ambientais e comportamentais com vistas à melhoria na atenção aos prematuros, envolvendo a família e, particularmente, a mulher/ mãe.

0 método é um cuidado complementar ao tratamento de alta tecnologia, que cria condições que permitam às mães vivenciar o saber-fazer e se responsabilizar. Salienta ainda que esta proposta incentiva a assistência ambulatorial e a perspectiva de desmedical ização e desospital ização do cuidado, assim que possível ${ }^{(5)}$.

O M C é desenvolvido em três etapas, estabelecidas pelo $\mathrm{M} \mathrm{S}^{(4)}$. A primeira deve iniciar logo após o nascimento de um recém-nascido pré-termo e/ ou de baixo peso e havendo a necessidade da permanência dessa criança em uma unidade de terapia intensiva neonatal (UTIN) e ou de cuidados intermediários, especial atenção deverá ser dada pela equipe assistencial no sentido de estimular a entrada dos pais na unidade, orientando-os sobre medidas de controle de infecção, procedimentos e as particularidades do ambiente, promover 0 toque adequado e o contato pele-a-pele com a criança, desde que as condições clínicas assim o permitam. T rabal ha-se o estímulo à lactação e a participação dos pais e familiares nos cuidados com 0 bebê. A posição Cangurud deve ser proposta sempre que possível e desejada.

$\mathrm{N}$ a segunda etapa o bebê encontra-se com clínica estável, nutrição enteral plena, ganho de peso regular diário maior que $15 \mathrm{~g}$ por pelo menos três dias e um peso superior a $1250 \mathrm{~g}$. Existe suporte familiar institucional e há interesse da mãe em permanecer com o seu filho na enfermaria de alojamento conjunto onde a posição canguru será realizada pelo maior período em que ambos acharem seguro e agradável. A vigilância e o apoio da equipe de saúde são fundamentais nessa etapa.

A terceira etapa, alta hospitalar com acompanhamento ambulatorial, só pode ocorrer se a criança estiver com um peso mínimo de $1500 \mathrm{~g}$, clinicamente estável e ganhando peso nos três dias que antecederem a alta, em al eitamento mater no exclusivo ou, na necessidade de complementação

\footnotetext{
d Posição Canguru: "consiste em colocar o recém-nascido em contato pele-a-pele no peito de um adulto, em decúbito prono, na posição vertical, com o mínimo de roupa possível"(4).
} 
da dieta, garantir que ela seja ofertada em copo ou seringa. A mãe e os familiares devem estar seguros quanto ao manuseio da criança e orientados quanto à importância de mantê-la, no domicílio, na posição canguru pelo maior tempo possível. É fundamental o compromisso de acompanhamento ambulatorial com três consultas na primeira semana, duas na segunda semana e na terceira semana em diante, uma consulta até atingir um peso mínimo de $2500 \mathrm{~g}$.

Por reconhecer a terceira etapa como aquela que dá continuidade à assistência ao recém-nascido pré-termo e/ ou de baixo peso após a alta hospitalar, exigindo diferentes modos adaptativos de todos os envolvidos, realizamos o presente projeto de pesquisa que tem como objetivos: investigar a experiência no processo de adaptação de famílias na terceira etapa do M C com recém-nascidos prétermo e/ ou de baixo peso e implementar a consulta de enfermagem com cada participante referente aos quatro modos adaptativos da T eoria de Roy.

\section{REFERENCIAL TEÓRICO. METODOLÓGICO}

Trata-se de uma Pesquisa Convergente-Assistencial (PCA), desenvolvida no período de outubro de 2006 a fevereiro de 2007 na unidade de $\mathrm{N}$ eonatologia do Hospital U niversitário da U niversidade Federal de Santa Catarina (HU/UFSC), tendo o M odelo de A daptação de Roy ${ }^{(6)}$ como referencial teórico.

Considerando a visão holística, os processos de inter ação e criatividade, a adaptação como um processo por meio do qual as pessoas, com pensamentos e sentimentos, criam suas interações humanas e ambientais encontramos no M odelo de Roy um leito propício ao cuidado baseado no respeito ao ser humano.

A opção por este referencial se fez a partir da necessidade sentida de articular teoria e prática na construção do conhecimento em enfermagem já que, segundo suas autoras, esta modalidade de pesquisa procura manter em todas as fases do processo investigativo, uma estreita relação com a prática assistencial, tendo como finalidade "encontrar alternativas para solucionar ou minimizar problemas, realizar mudanças e introduzir inovações na prática"(7).

0 presente estudo envolveu seis mães e familiares com seus bebês recém-nascidos pré-termo e/ ou de baixo peso internados na unidade de neonatologia e que ingressaram na terceira etapa do M C durante o período de coleta de dados. Foi rigorosamente considerado o consentimento livre e esclarecido das mães e familiares em participar do estudo.

I mportante ressaltar que na pesquisa de natureza qualitativa, e, portanto também na PCA, não são estabelecidos critérios rígidos para a seleção e o tamanho da amostra, devendo estes, ser delineados com base na necessidade de informação. Alguns autores sugerem como princípio orientador, a saturação dos dados, ou seja, "amostrar até 0 ponto em que não é obtida nenhuma informação nova e é atingida a redundância"(8).

Durante a pesquisa, utilizamos informações registradas em prontuário para identificar dados maternos e paternos, dados do parto e do recémnascido prétermo e/ ou de baixo peso durante sua internação na unidade de neonatologia até seu ingresso na terceira etapa do M C e de informações complementares prestadas pelos familiares dos bebês.

$\mathrm{N}$ a coleta de dados, buscamos interagir através da observação do processo que desospitaliza recém-nascidos pré-termo e/ ou de baixo peso, buscando informações referentes ao fenômeno estudado. Desta forma os encontros, as consultas de enfermagem em terceira etapa do M C, foram planejados de modo que a pesquisa e a prática convergissem no processo de cuidar do modelo adaptativo de Roy a eles vinculados.

A técnica principal utilizada foi a observação participante, pela propriedade que possui de captar uma variedade de fenômenos de uma situação social, os quais não podem ser obtidos unicamente por meio de entrevistas ${ }^{(9)}$.

N este estudo, a observação auxiliou a conhecer 0 que as mães e familiares faziam, falavam e com quem falavam, e, suas expressões não verbais quando retornavam para a consulta na terceira etapa. T ambém apuramos o olhar sobre o recémnascido buscando suas respostas adaptativas sob cuidado domiciliar e seu comportamento durante as avaliações pondo-estaturais, processo de amamentação, vigília ou repouso durante as conversas com os pais e familiares que acompanharam os bebês nos retornos.

$\mathrm{Na}$ sequência utilizamos a entrevista individual, uma interação face a face com o entrevistado, na modalidade semi-estruturada que parte de 
tópicos relacionados ao tema de pesquisa, oportunizando 0 aprofundamento e a focalização no assunto à medida que a interação se desenvolve.

$\mathrm{N}$ a entrevista promovemos a sistematização sugerida, para a terceira etapa, pelo M inistério da Saúde através da N or ma de A tenção H umanizada ao Recém- $\mathrm{N}$ ascido de Baixo Peso(4).

$\mathrm{Na}$ coleta de dados, Iançamos mão também dos seguintes instrumentos de registro: fotos, gravações e transcrição das fitas com autorização dos participantes; utilização de um diário de campo, elaborado após cada encontro, no qual registramos dados relativos a cada vivência, incluindo a presença e envolvimento dos participantes no processo através da comunicação verbal e não verbal, bem como reflexões pessoais.

O peracionalmente, no processo analítico, utilizamos: processo de apreensão, processo de síntese, processo de teorização, processo de transferência ${ }^{(7)}$.

Esta pesquisa respeitou os princípios de beneficência, não mal eficência, justiça e autonomia, preconizados pela Resolução 196/ 96 do Conselho N acional de Saúde ${ }^{(10)}$, e os princípios do Código de Ética profissional(11). 0 projeto foi submetido ao Comitê de Ética em Pesquisa da U F SC, sendo aprovado sob o parecer $n=237 / 2006$.

\section{RESULT ADOS E DISCUSSÕES}

Desenvolvendo este estudo enquanto pesquisadoras, ocorreu um constante crescimento e envolvimento com a PCA, representado na Figura 1 , a seguir, a relação direta entre a consulta de enfermagem, as entrevistas, as observações, os registros e a PCA.

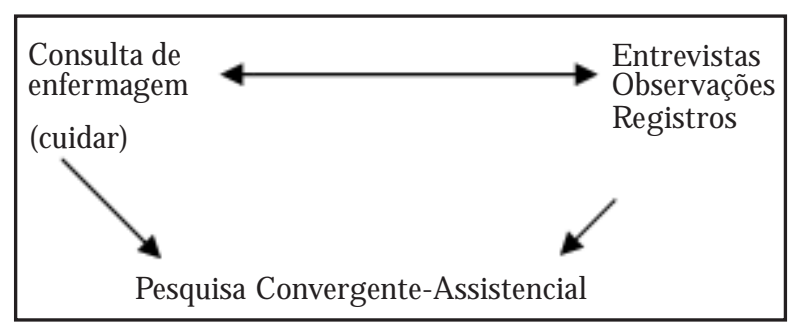

Figura 1 - Processo de cuidar.

No processo de cuidar, que foi ajustado a partir do processo de enfermagem proposto por Roy, abstraímos lições de vida das mães e familiares, de enfrentamento, de adaptações originadas por estímulos, ora focais, ora contextuais, num processo de retroalimentação complexo como vivenciamos ser a teoria de adaptação. A primeira etapa foi a de coleta de dados por observação e entrevista.

$\mathrm{N}$ a segunda etapa, categorias diagnósticas, investigamos os indicadores de adaptação positiva e os problemas comuns de adaptação nos quatro modos de adaptação descritos por Roy (fisiológico, autoconceito, função de papel e interdependência). Para tanto se observou os comportamentos dos envolvidos, respostas das mães e familiares junto às do seu bebê frente o cuidado realizado pelos mesmos durante a terceira etapa.

$\mathrm{N}$ a terceira etapa, o diagnóstico de enfermagem, um exercício de autonomia profissional, facilitando a inter ação com os sujeitos significativos, dando clareza ao manejo necessário para o processo adaptativo de acordo com as necessidades individuais ou coletivas. I dentificadas as adaptações positivas estas foram estimuladas se necessárias ao processo de cuidar e os problemas de adaptação que exigiam articulações do enfermeiro receberam atenção específica.

Diagnóstico de enfermagem elaborado seguia-se com a quarta etapa, a descrição dos cuidados de enfermagem, estabelecendo as metas com clareza nos resultados que se esperava alcançar. Este plano foi estabelecido com a mãe, pai e familiares para os comportamentos a serem alcançados por eles e seu bebê.

$M$ etas estabelecidas, e, buscando reconhecer 0 al cance das mesmas realizava-se a quinta etapa, a avaliação.

D entro do controle sistemático sugerido pelo M inistério da Saúde ${ }^{(4)}$, observou-se, para fins de avaliação do processo da prática, o trabalho com a demanda da família em relação a avaliação pôndero-estatural, exame clínico sumário, avaliação do equilíbrio psicoafetivo mãe-bebê, diagnóstico, tratamento e orientação, promoção do al eitamento materno, imunização (anti-hepatite B), revisão do sumário de alta e atenção para controles especiais. 0 processo avaliativo transcorreu sempre no finalizar de cada retor no em terceira etapa do M étodo $M$ ãe-Canguru.

N este estudo, na realidade do HU / UFSC, observamos que o peso dos bebês na alta é de $1.750 \mathrm{~g}$ a $1.900 \mathrm{~g}$, idade gestacional corrigida de $34 \mathrm{~s} 1 \mathrm{~d}$ a 39s1d, mamando ao peito e em alguns casos com complemento, o primeiro retorno acontece dentro de 72 a 120 horas e a frequência das consultas é de duas por semana até 0 peso de $2.000 \mathrm{~g}$. Estes 
dados são registrados em formulário específico da terceira etapa do M C, mas sentimos falta de mais riquezas nas anotações que nos permitam uma leitura mais próxima da realidade de cada família.

Propomos recriar o formulário inserindo dados como realização do Canguru ( $<6$ horas/ dia 6 a 12 horas/ dia - > 12 horas/ dia); ganho ponderal diário; condutas em curso (medicações); imunizações; rede social de apoio; visita domiciliar e na al ta identificar o ambulatório de desenvolvimento (alto risco ou baixo risco).

Investigar as experiências no processo de adaptação de mães e familiares especificamente na terceira etapa do M C nos remete a explicação que a atenção M C questiona abertamente a atitude paternalista da equipe de profissionais e as rotinas com que se tem praticado os cuidados, porque a sua implantação exige uma redefinição dos papéis sociais já estipulados, pois o conflito está na luta dos movimentos de humanização perinatal contra um esquema profissional que pratica uma modalidade de atenção que se apodera da vida dos pais e dos recém-nascidos, não compartiIhando decisões ${ }^{(12)}$.

A presentamos três categorias primárias das representações que convergiram do meio-tempo entre a desospitalização precoce e o primeiro retorno na terceira etapa do $M C$, com as vivências que contribuíram para a adaptação cuidativa e as que provocaram circunstâncias (des)adaptativas aos sujeitos deste estudo.

A primeira categoria converge do meio-tempo entre a desospitalização precoce e o primeiro retorno na terceira etapa do M C. D esta extraímos cinco subcategorias convergentes: Valorando 0 aleitamento materno; Percebendo necessidades de manejo com RN ; A felicidade e o medo ao sair do hospital; Primeira noite nenhuma mãe dorme; e Reconhecendo e ativando cuidados.

A segunda, categorias adaptativas, convergentes dos retor nos na terceira etapa do M C. Percepções de ações para adaptação cuidativa potencializando a inter-relação de mães e familiares com o recém-nascido prétermo e/ ou de baixo peso, com cinco subcategorias convergentes adaptativas: $M$ amãe eu quero mamar; $M$ eu bebê quer isso, quer aquilo. Precisa disso; $M$ eu bebê está crescendo; N osso bebê, nossa família: é bom estarmos juntos; e Coração tranquilo.

A terceira, categorias (des)adaptativas, convergentes dos retornos na terceira etapa do M C.
Percepções que provocaram circunstâncias modificando comportamentos os quais necessitaram ser articulados para sair da convergência (des) adaptativa, tendo cinco subcategorias: M eu leite é pouco, meu peito dói; Para que esses exames/por que esses acompanhamentos?; E u preciso de um especialista; 0 que me fez descuidar do bebê: minha cabeça ou meu coração?; e Amar e estar junto, ou só estar junto?

0 papel da enfermeira na terceira etapa do MC vai além do supervisionar, coordenar, encaminhar e prescrever. Os resultados mostram que é preciso receber, colaborar no acolhimento amoroso, estabelecer confiança, distribuir qualidade independente da quantidade, desenvolver um ambiente promotor de estímulos positivos, renovar a comunicação interdisciplinar, participar das avaliações de desenvolvimento do bebê, reforçar a relação mãe/ pai/ bebê, mostrar os achados positivos nos retornos, informando os pais por meio de uma linguagem simples do primeiro ao último retorno quando da alta da terceira etapa.

A adaptação no ambiente domiciliar varia de acordo com os cuidados e papéis diários assumidos pela mãe e familiares e pelos resultados obtidos nas consultas em terceira etapa. Sentimentos ambíguos como medo, ansiedade, preocupação, incertezas afetam 0 autoconceito e o funcionamento familiar, pois se mobilizam, muitas vezes, inconscientemente, por sentirem-se ligados a uma criança que poderá morrer a qualquer momento.

As percepções identificadas estão no contexto de como a mãe e o pai valorizam a amamentação, suas formas de manejar o bebê para evitar o estresse quando é preciso manter mamadas de $3 / 3$ horas, lidar com a sonolência, ofer tar o complemento realmente após as mamadas, por meio da sucção nutritiva e sem promover o uso de mamadeiras/ chucas, conforme aceitação e não como prioridade.

Recente estudo reforça que a amamentação não deve ser vista como responsabilidade exclusiva da mulher, que está envolvida em sentimentos, emoções e contradições, mas, sim, de todo o contexto sócio-histórico-biológico que extrapola o binômio mãe-filho(13).

Entender que o choro é uma manifestação de busca de proximidade, de toque, de fala, talvez de um simples incômodo que é resolvido ao trocar as fraldas do bebê, ou, promover a sucção não nutritiva permitindo que sugue no dedo mínimo do cuidador para obter efeito calmante, ou ainda a 
melhor hora de posicionar o recém-nascido no cuidado canguru, ou seja, o contato pele-a-pele.

A posição canguru não foi percebida, por todas as seis famílias deste estudo, como um cuidado promotor de desenvolvimento do bebê ou do afeto entre o binômio que o realiza. $\mathrm{N} o$ entanto foi resgatada enquanto meta construída em conjunto nas consultas de enfermagem, tendo sido realizada por todas as mães, quatro pais, uma avó, duas irmãs e um tio.

Estudos realizados confirmam que a prática do Canguru contribuiu, de forma efetiva, para 0 aumento do senso de competência dos pais, atuando como capacitador para o cuidado desses prematuros em domicílio(14-17).

A cuidadora principal, a mãe, também se percebe de forma diferenciada na terceira etapa, busca orientações para sua alimentação, cuidados com as mamas, métodos contraceptivos ou tratamentos ginecológicos específicos.

0 apoio às mães em necessidades de exames complementares de seus filhos exigiu trabalhoso estímulo contextual, o que foi percebido por elas através do processo educativo sobre triagem neonatal e por se sentirem amparadas durante suas oscilações emocionais alterando estímulos que contribuíram para comportamentos ineficazes. A creditamos que tenha ocorrido uma adequação afetiva que através das inter-relações insere a pessoa como um ser social.

A culpa irá acompanhar os pais que tiverem bebês antecipadamente, independente da gravidade e dos problemas manifestados. 0 fato é que estes pais irão sentir-se responsáveis por uma ação ou omissão que ocasionou este prejuízo ao recémnascido(18).

Percebemos neste estudo que pai, mãe e familiares não procuram o isolamento. Eles, na terceira etapa, onde são os atores principais, querem desenvolver competências e focam a enfermeira nesta busca, e isto é gratificante, trabalhoso, mas sempre gratificante. É sentir de fato a vibração do cuidado adaptativo. No processo de cuidar abstraímos lições de vida das mães e familiares, de enfrentamento, de adaptações originadas por estímulos, ora focais, ora contextuais, num processo de retroalimentação complexo como vivenciamos ser a teoria de adaptação de Roy.

Os resultados deste trabalho indicam a necessidade de repensar as atuações interdisciplinares no campo estudado, rever critérios da alta da terceira etapa além da aferição pôndero-estatural necessidade contínua de acompanhamento no processo de amamentação, no cuidado canguru, de suporte psicoafetivo e na organização de papéis.

\section{CONSIDERAÇÕES FINAIS}

0 modelo de adaptação de Roy renovou nossa dimensão educacional permitindo-nos criar uma metodologia própria, prática e incomparável frente o exercício da percepção do ambiente, ser humano, enfer magem, saúde-doença, adaptação e M C.

Com clareza do referencial teórico propusemos a inserção do modelo de adaptação de Roy motivadas de que os comportamentos vêm do interior do organismo, pelos registros de crenças e valores culturais, vivências e níveis de exigência gerados no convívio social, ambientes que facilitam ou não a adaptação do ser humano conforme sua potencialidade ou fragilidade máxima.

0 marco conceitual inseriu um exercício profissional desafiador, instigante e apaixonante. Ao desvendar leituras e sustentar o referencial teórico sistematizado ocorreu a conexão entre nossas expectativas enquanto enfermeiras assistenciais e nossas crenças pessoais. A partir de então a construção do estudo com metas de promover respostas adaptativas em harmonia com o respeito ao ser humano e a sua capacidade de enfrentamento em diferentes ocasiões.

$\mathrm{N}$ a sociedade emergente as mudanças fazem parte do dia-a-dia, são cada vez mais rápidas e profundas e exigem constantes esforços de adaptação. U m desafio para o novo milênio, o de prepará-las para uma certa invulnerabilidade que Ihes permita resistir a situações adversas que a vida proporciona, pelo que se torna imperioso identificar os fatores de risco e particularmente os fatores de proteção pessoais e interpessoais ${ }^{(19)}$.

Chegar à terceira etapa do M C é uma nova transição, outra mudança de situação para a família expondo-a a inúmeras e novas mobilizações. A mãe e os familiares precisam fortalecer suas expectativas de cuidadores capazes, independentes e conscientes. A terceira etapa do M C nos per mite um feedback fantástico das etapas anteriores e remete pais e bebês envoltos em maior segurança para 0 acompanhamento no ambulatório de pediatria ${ }^{(20)}$

A importância da percepção em manter vínculos afetivos no domicílio torna a desospitaliza- 
ção precoce menos negativa. Entendemos que 0 cotidiano da família alterado pela hospitalização prolongada do seu bebê precisa de apoio para que se reorganizem durante a terceira etapa do M C onde terão novas incumbências, hábitos diferentes al ém de aprender a lidar com o cuidado adaptativo em período integral.

Esperamos ter contribuído com um enfoque diferenciado sobre a literatura existente sobre a metodologia canguru, pois abordando especificamente a vivência da terceira etapa teremos um recorte de preposições teórico-práticas que desafiam o ideal da humanização.

Temos na terceira etapa, a oportunidade de retroalimentar o sistema cuidativo. $E$, neste contexto, beneficiamos o recém-nascido de baixo peso na sua individualidade, mas necessariamente relacionado com outros seres humanos, no tempo e no espaço. Vivenciamos aceitação, satisfação, retivemos informações, selecionamos idéias, criamos implementando, coletando e identificando nas categorias resultantes do processo de compreensão 0 aflorar do exercício da enfermagem além da fase intra-hospitalar, contribuindo com o movimento contínuo de humanização para incorporação do recém-nascido como um indivíduo, incluso socialmente em uma família, agente da promoção de sua própria saúde, que permite que seus representantes legítimos defendam os seus melhores interesses.

\section{REFERÊNCIAS}

1 Charpak N, CalumeZF, H amel A. O método canguru: pais e familiares dos bebês prematuros podem substituir as incubadoras. Rio de Janeiro: M ac G raw Hill; 1999.

2 Costa R. Reflexões da equipe de saúde sobre o método mãe-canguru em uma unidade de neonatologia: um diálogo fundamentado na abordagem problematizadora [ dissertação] . F lorianópolis: U niversidade Federal de Santa Catarina; 2005.

3 Carvalho M R, Prochnik M . M étodo mãe-canguru de atenção ao prematuro. Rio de Janeiro: BN DE S; 1999.

4 M inistério da Saúde (BR), Secretaria de Políticas de Saúde, Ár rea T emática da Saúde da Criança. A tenção humanizada ao recém-nascido de baixo peso: método canguru: manual do curso. Brasília (DF); 2002.

5 X avier CC. 0 método cuidado mãe canguru [ Internet]. Belo H orizonte: U F M G ; 2002 [ citado 2005 ago 28] . D isponível em: http:/ / www.medicina.ufmg. br/ edump/ ped/ canguru.htm.

6 Roy SC. Introduction to nursing an adaptation model. Englewood Cliffs: Prentice-Hall; 1984.

7 T rentini M , Paim L. Pesquisa convergente-assistencial : um desenho que une o saber fazer e o saber pensar na prática assistencial em saúde-enfermagem. 2aㅡ ed. Florianópolis: I nsular; 2004.

8 Polit D F, Beck CT, H ungler BP. F undamentos de pesquisa em enfermagem: métodos, avaliação e utilização. 5a ed. Porto Alegre: Artmed; 2001.

9 M inayo M CS. Pesquisa social: teoria método e criatividade. 9ạ ed. Petrópolis: Vozes; 1994.

10 M inistério da Saúde (BR ), Consel ho N acional de Saúde. Resolução 196, de 10 de outubro de 1996: diretrizes e normas regulamentadoras de pesquisa envolvendo seres humanos. Brasília (DF ); 1996.

11 Conselho Federal de Enfermagem. Resolução COFEN no 240, de 30 de agosto de 2000: aprova o Código de Ética dos Profissionais de E nfermagem e dá outras providências. Brasília (D F ); 2000.

12 Cecchetto S. M ãe canguru: tecnologia perinatal humana: parte l : uma abordagem pela bi oética. In: Carvalho M R, T amez, R N , organizadores. Amamentação: bases científicas para a prática profissional. R io de Janeiro: G uanabara Koogan; 2002. p. 132-6.

13 Braga F B, M achado M M T, Bosi M L M. A mamentação exclusiva de recém-nascidos prematuros: percepções e experiências de lactantes usuárias de um serviço público especializado. Rev N utr. 2008;21(3): 293-302.

14 Cabral IE, Rodrigues EC. 0 método mãe canguru em uma mater nidade do R io de Janeiro 2000-2002: necessidades da criança e demanda de educação em saúde para os pais. T exto Contexto E nferm [ Internet] . 2006 [ citado 2008 maio 27];15(4):629-36. D isponível em: http:/ / www.scielo.br/ pdf/ tce/ v15n4/ v15n4a11.pdf.

15 Bousso RS. Buscando preservar a integridade da unidade familiar: a família vivendo a experiência de ter um filho na UTI pediátrica [ tese]. São Paulo: E scola de E nfermagem, U niversidade de São Paulo; 1999.

16 Javorski M, Caetano LC, Vasconcelos M GL, L eite AM , Scochi CG S. As representações sociais do al ei- 
tamento materno para mãe de prematuros em unidade de cuidado canguru. R ev L atino-A m E nfermagem [ I nternet] . 2004 [ citado 2008 maio 27] ;12(6): 890-8. Disponível em: http:/ / www.scielo.br/ pdf/ rlae/ v12n6/ v12n6a07.pdf.

17 M artins A J VS, Santos I M M . Vivendo do outro lado do método canguru: a experiência materna. Rev Eletrônica E nferm [ Internet] . 2008 [ citado 2008 dez 27] ;10(3):703-10. Disponível em: http:/ / www.fen. ufg.br/ revista/ v10/ n3/ v10n3a16.htm.

18 Pereira AM S. Resiliência, personal idade, stress e estratégias de coping. In: T avares J, organizador. Re- siliência e educação. São Paulo: Cortez; 2001. p. 77 94.

19 Fraga IT G, Pedro ENR. Sentimentos das mães de recém-nascidos prematuros: implicações para a enfermagem. Rev G aúcha Enferm. 2004;25(1):8997.

20 Borck M. Terceira etapa do método mãe-canguru: convergência de práticas investigativas e de cuidado no processo de adaptação de famílias com recémnascidos pré-termo e/ ou de baixo peso [ dissertação] . F Iorianópolis: U niver sidade Federal de Santa Catarina; 2007.

\section{E ndereço da autora / Dirección del autor /}

\section{Author's address:}

M árcia Borck

Rua Prof. a M aria F lora Pausewang

Campus U niversitário, HU / U F SC

88040-970, F lorianópolis, SC

E-mail:marcia.huufsc@yahoo.com.br
Recebido em: 24/ 06/ 2010

A provado em: 20/ 12/ 2010 